\title{
A Note on Cleanthes and Early Stoic Cosmogony
}

\author{
Benjamin Harriman \\ The University of Edinburgh, Edinburgh, UK \\ benjamin.harriman@ed.ac.uk
}

Received July 2019 | Accepted December 2019

\begin{abstract}
Our primary evidence for the contribution of Cleanthes, the second Stoic scholarch, to the school's distinctive theory of cyclical ekpyrosis (conflagration) is limited to a single difficult passage found in Stobaeus attributed to Arius Didymus. Interpretations of this text have largely proceeded by emendation (von Arnim, Meerwaldt) or claims of misconstrual or misunderstanding (Hahm). In recent studies, Salles and Hensley have taken the passage at face value and reconstructed opposed interpretations of Cleanthes' position. The former suggests that it differs significantly from that of Zeno and Chrysippus. Both the sequence of elemental transformation and its scope are said to be challenged by Cleanthes, suggesting cosmogony was a deeply controversial area in the early Stoa. I resist this interpretation of the evidence while also attempting to read the text without textual correction. Hensley, on the other hand, finds all three to be in strict harmony. Here I advocate for a middle ground where Cleanthes is closer to the positions of both Zeno and Chrysippus, but I also find room for his development of Stoic cosmogony as composed of a series of discrete stages radiating outwards from the middle. We are left with a clearer, more nuanced picture of how Stoic natural philosophy develops in its early period.
\end{abstract}

\section{Keywords}

Stoics - Cleanthes - Chrysippus - cosmogony - conflagration

One point of harmony among the triad of early Stoic scholarchs was their shared commitment to the theory of an infinite cycle of total conflagrations of 
the cosmos. ${ }^{1}$ Zeno, Cleanthes, and Chrysippus are all reported, in one form or another, to accept that the current cosmological order will be destroyed into fire and that another (identical) cosmic order will emerge in its place. ${ }^{2}$ How such a commitment to world destruction squares with the equally strong Stoic thesis of divine providentialism is not immediately obvious, and it is little surprise that many later Stoics - Zeno of Tarsus, Boethus of Sidon, and Panaetius among them-all either refused to commit to the theory of conflagration or denied it outright. ${ }^{3}$

Yet even in the apparent concord of the early Stoa, there are reasons-or so it has been thought - to think that the conflagration was a point of some disagreement, particularly on the question of how the cyclical process moves from fiery destruction to the next step of world-creation, or cosmogony. John Cooper, for example, in a recent interpretation of the taxonomy of the Stoic use of 'element' found in Stobaeus 129.1-130.20 Wachsmuth, suggests that we must understand Chrysippus as committed to a three-stage process of the cosmic transformation of god. ${ }^{4}$ Beginning from an absolute originary stage, described as a flash ( $\alpha \dot{v} \eta \dot{\eta})$, and conceived of as the bare substance that results when the active and passive principles are present, the process turns next to a protostage where primitive fire, air, and water result. Finally, proto-water turns into the familiar four elements from which the world is constructed. Importantly, Chrysippus' cosmogony and, particularly, his identification of the absolute originary flash is to be understood as a clarification of Zeno and Cleanthes, as both appear to have failed to separate such a substance from some form of fire. Cooper suggests that such a failure leads to the inconsistency, corrected by Chrysippus, of assuming a primitive role for fire while also suggesting that the element itself only comes about in a more advanced stage of elemental transformation.

An even more polemical note is detected by Ricardo Salles in Cleanthes' positions on the extent of the conflagration and the elemental beginnings of a new cosmic order. ${ }^{5}$ Using our primary source for Cleanthes' cosmogony (Arius

1 I thank Damian Caluori and the Edinburgh ancient philosophy reading group for comments and discussion. The Leverhulme Foundation generously supported this research. I also thank the editor of this journal and Gerard Boter for their helpful advice.

2 D.L. 7.142, see below. Cf. SVF 2.605, 1.98, 1.510, and Alexander of Lycopolis 19.2-4 (LS 46I) for the conflagration. On the 'everlasting recurrence', see the texts collected in LS 52 .

3 SVF 3.1 Zeno Tarsensis 5; SVF 3.6 Boethus Sidonius 7. For Panaetius, see Cic. N.D. 2.46. For a discussion of the compatibility of providence and cosmic destruction here, see the classic account of Mansfeld 1979 .

4 Cooper 2009.

5 Salles 2015. See Salles 2009 for an account of how Chrysippus advanced on Cleanthes' elemental theory by arguing that elemental transformation occurs by the mere change in density of fire rather than by outright destruction. 
Didymus, fr. 38, Stob. $1.17=S V F$ 1.497), he presents three points of disagreement with both Zeno and Chrysippus. (1) Cleanthes holds that the fire of the conflagration is never totally extinguished and that elemental fire is a 'remnant' of this; (2) elemental water is made from earth rather than the other way around; and (3) there is matter in the cosmos (i.e. residual earth) that is not combustible. A significant upshot of this is that two of the four elements (fire and earth) are said to be present during the process of world formation as survivors of the conflagration.

These positions are clearly at odds with what is traditionally understood as the standard account of Stoic cosmogony, found in Diogenes Laertius:

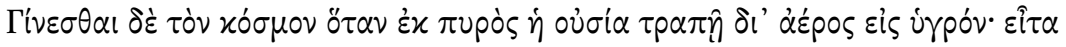

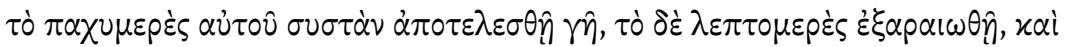

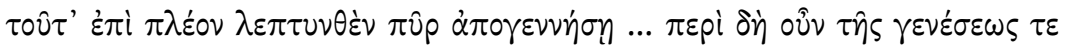

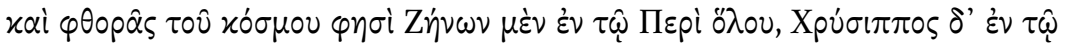

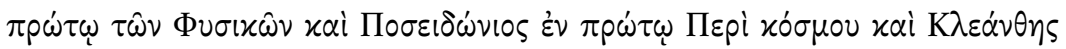

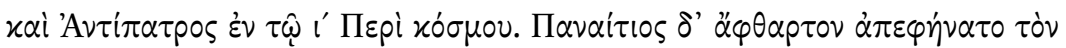
xó $\sigma \mu \mathrm{ov}^{6} 6$

The world is created when the substance is turned from fire through air into moisture; then the thicker parts of the moisture condense and end up as earth, while the finer parts are made into air, and when they have been thinned further still, they produce fire ... The generation and the destruction of the world are discussed by Zeno in his treatise On the Whole, by Chrysippus in the first book of his Physics, by Posidonius in the first book of his work On the Cosmos, by Cleanthes, and by Antipater in his tenth book On the Cosmos. Panaetius, however, maintained that the world is indestructible.

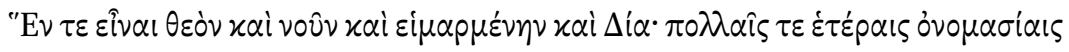

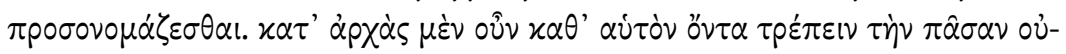

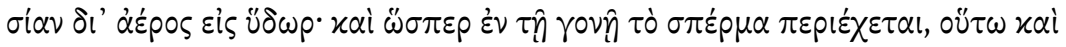

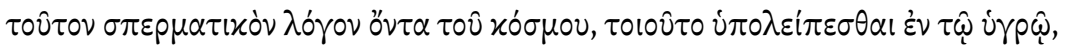

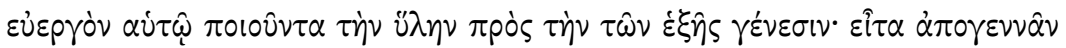

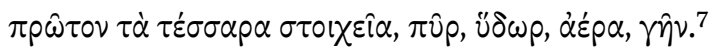

6 D.L. 7.142, trans. after LS. I follow the edition of Dorandi 2013, with the exception of the first

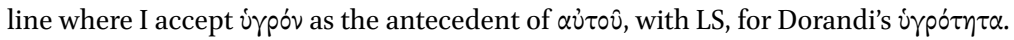

7 D.L. 7.135-136, following Dorandi 2013; trans. after LS. 
God, intelligence, fate, and Zeus are all one, and many other names are applied to him. In the beginning all by himself he turned the whole of substance through air into water. Just as sperm is enveloped in the seminal fluid, so god, who is the seminal principle of the world, remains behind as such in the moisture, making matter serviceable to himself for the next stage of creation. He then creates first of all the four elements, fire, water, air, earth.

From these two passages, it appears that after the conflagration, 'substance' is transformed by god, as the active principle, through fire into a preliminary state of air and, then, into water. From this final, primitive stage of water, the four elements are generated, and the actual business of cosmic ordering accomplished. There are several points here that demand clarification, including whether 'substance' (ovं $\left.\sigma^{\prime} \alpha\right)$ is, in its initial state, identical with some form of fire, and how the primitive (or, 'proto') elements relate to their cosmic counterparts. ${ }^{8}$ However, the salient points of the transformation of fire, through air, into water and the generation of all four cosmic elements from water seem relatively clear, and I will call this the 'traditional' or 'orthodox' account below. Importantly, Diogenes in 7.142 gives us every reason to think that Cleanthes endorsed the main principles of such account, and cosmogonic descriptions in later Stoic texts, including those of Seneca and Cornutus, follow a broadly similar formula. ${ }^{9}$

Salles's reconstruction of what he takes to be Cleanthes' highly polemical understanding is based on a very difficult passage from Stobaeus that has long puzzled interpreters. Von Arnim and Meerwaldt could only make sense of the text after emendation. ${ }^{10} \mathrm{Hahm}$, carefully noting many of the issues with earlier

8 See Gourinat 2009, 59-62 for discussion of both of these questions. On the latter point, Cooper 2009, 105-113 suggests that the 'proto-elements' are distinct in kind from their cosmic analogues. Salles 2015, 17-18 argues for an understanding of primitive water as the same substance as the familiar element, distinguished only by not being in its natural place. Gourinat raises a related argument for primitive fire/elemental fire. Although not without some hesitation, I insist on the difference between proto and cosmic elements below. The texts do suggest such a difference, and we should be careful not to import illicitly any of the standard characteristics of the cosmic elements into our discussion of the proto stage. Whether we are given a convincing argument for how proto and cosmic elements are to be distinguished is a different matter.

$9 \quad$ Sen. Nat. 3.10.3-4, 13.1; Corn. 29.10-11, 53.3-5.

10 Cf. von Arnim 1921, 563-564 and the emendations made in $S V F$ 1.497. This has been subject to careful analysis by Meerwaldt 1951, 44-53. He, too, resorts to emendation, but, at certain points in his discussion, he comes nearest to the spirit of the reading I propose. 
readings, examines the differences in Stobaeus' text from the standard picture in Diogenes only to dismiss them as a 'misinterpretation' of Cleanthes' faithful elaboration of the Zenonian view. ${ }^{11}$

In this respect, Salles's attempt to take the passage at face value is notable and, I think, ultimately the procedure we must adopt. However, his reconstruction of Cleanthes' view of cosmogony is not, I think, adequately supported by the text. In addition to Salles, a very recent contribution to the interpretation of early Stoic cosmogonical accounts has been offered by Ian Hensley. ${ }^{12} \mathrm{He}$ defends three major claims: (1) some of the fire of the conflagration remains throughout the cosmogony; (2) there is no need to posit any proto-elements that arise during its early stages; and (3) the early Stoics endorse the 'same' theory of world formation.

On the last point, at least, what I will suggest below bears a significant resemblance; although I am hesitant to call the theories of the early Stoics the 'same' in a particularly strong sense. 'Mutually consistent' better captures the idiosyncrasies suggested by our evidence and the development that is most plausibly attributed to Cleanthes. Hensley also reconstructs some of Cleanthes' theory along similar lines to what I will suggest, appropriately attending, for example, to the progressive quality of the $\delta 1 \alpha x^{\prime} \sigma \mu \eta \sigma i \varsigma$ that Stobaeus' testimony suggests. We do differ though on how these progressive stages are to be construed, and particularly on the movement of fire.

However, on the first two points, I suggest a different account. Hensley insists that the fire of the conflagration persists throughout the stages of the cosmogony. Certainly, as he indicates, Philo's testimony (Aet. Mun. 89-91), though hostile, does confirm the importance of fire as the source of motion and generation for the Stoics. It is also true that the evidence quoted above from Diogenes confirms that soul is left behind in cosmogonic water. Of course, for the Stoics, soul is corporeal $\pi \nu \varepsilon \hat{\mu} \mu \alpha$, or, at the very least, to be identified with fire. ${ }^{13}$

Yet it is unclear to me that this is rightly understood as the persistence of the fire of the conflagration. Stobaeus' account of designing and undesigning fire helps here:

\footnotetext{
11 Hahm 1977, 240-248. See also Pearson 1891, 252-255.

12 Hensley forthcoming, ${ }^{*} 1^{-}{ }^{*} 27$.

13 See $S V F$ 2.442, Nemesius 70.6-71.4, and Cic. N.D. 2.23-25.
} 


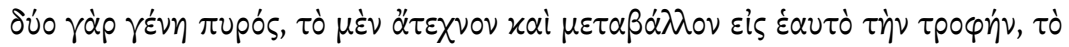

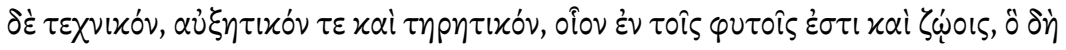

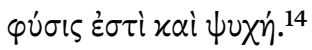

For there are two kinds of fire: one is undesigning and converts fuel into itself; the other is designing, causing growth and preservation, as is the case in plants and animals where it is physique and soul respectively.

With this distinction in mind, what is suggested is not that the fire of the conflagration survives (surely it is just the exhaustion of cosmic fire's fuel that brings about conflagration's end and the rebirth of the cosmos), but that the permanent feature of the universe is this designing fire, understood, as Long and Sedley put it, "the necessary consequence of god's constant conjunction with matter".15

Consider how Philo understands this distinction in his account:

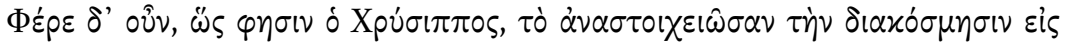

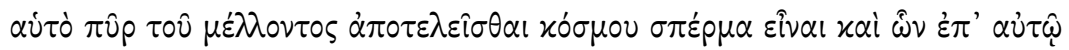

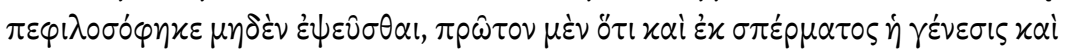
$\varepsilon i \zeta \sigma \pi \dot{\varepsilon} \rho \mu \alpha \dot{\eta} \alpha \dot{\alpha} \alpha \dot{\lambda} \nu \sigma \iota \varphi^{16}$

Now suppose that as Chrysippus says the fire which has resolved the world as constructed into itself is the seed of the world which will result and that there is no fallacy in his theories on the subject, primarily that its generation comes from seed and its resolution passes into seed.

His report then need not suggest that the conflagration's fire persists throughout the cosmogony, but that the distinction between designing and undesigning fire (with the first associated with 'the seed of the world') that Stobaeus associates with the Stoa from Zeno onwards, commits them to the eternity of universe, despite their protestations. ${ }^{17}$

14 Stob. 1.213.15-21 = SVF 1.120, part. trans. LS. Cf. Stobaeus' discussion $(1.129 \cdot 2-130.13=S V F$ 2.413, part) of Chrysippus' tripartite division of the term 'element', where fire is called the element par excellence, pointing to its unique role in Stoic physics.

15 LS 278.

16 Philo, Aet. Mun. 94. Trans. Colson. That designing fire is to be associated with the seminal principle discussed by Diogenes is suggested by Aët. 1.7.33 $=S V F$ 2.1027.

17 Cf. Stob. 1.152-153 = SVF 1.102. This passage from Stobaeus confirms the sequence reported by Diogenes and further suggests that cosmic, elemental fire is only produced through the

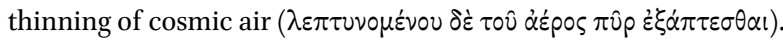


Nor do I believe it is correct to term the cosmogonic transformations as 'par-

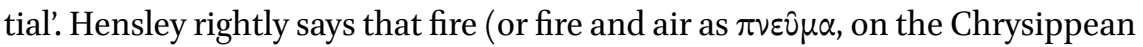
theory) is responsible for the maintaining the tension, or tenor, of the other elements and everything else in the universe. Yet it is misleading to say that the cosmogonic changes from fire to air to water are less than total. Cosmogonic water is not properly understood as partially water and partially fire. It is the active principle itself, identified with god, reason, vital heat, and fire, that qualifies bare ov $\sigma^{\prime} \alpha$ as the passive principle and makes it water. Water is, in its very essence, matter qualified by the active, designing principle. ${ }^{18}$ It is not in spite of, but because of, this active principle that the elements are individuated from undifferentiated matter. ${ }^{19}$ On this analysis, it makes as little sense to claim that the presence of the active principle negates the totality of an elemental transformation as thinking that the presence of passive matter, previously qualified, would do so. Only if we keep in mind the crucial distinction between designing and undesigning fire, associated with Zeno and the beginnings of the school, can we make sense of the Stoic god as divine fire and his place throughout the cosmogony.

With this in mind, the evidence of Seneca confirming the extent of cosmogonic changes as total (Nat. 3.13) need not be dismissed, with Hensley, as an outlier. Fire, Seneca says, is extinguished, and what remains is water. Yet it is only because the water is structured and individuated by the divine active principle that Seneca can also insist of water that in hoc futuri mundi spem latere. ${ }^{20}$

18 What is this quality? The common quality of water is a certain portion of fire that differentiates substance and corresponds to the universal concept of water. See LS vol. 1, 174 and $S V F 2.378$ and 2.398 .

19 Of course, it is the impossibility of distinguishing between bare substance and the qualified body through sense-perception that leads to Plutarch's famous criticism of the Stoic genera $($ De comm. not. $=$ Mor. $1083 \mathrm{a}-1084 \mathrm{a})$.

20 Sen. Nat. 3.13. I leave to one side here Hensley's interesting attempt to deny the need for understanding proto-elements in the Stoic cosmogony. His appeal to Stoic embryology to explain the non-linear sequence that Diogenes suggests is appealing, but the text there reserves the word $\sigma \tau 0 \chi \chi \varepsilon \hat{\varepsilon} \alpha$ for the latter stage of the cosmic elements, indicating some distinction is to be made. The evidence from Stob. 1.129.2-130.13 = SVF 2.413, part., cataloguing the different uses of the term 'element' in Chrysippus, with only one devoted to the four elements of cosmic composition, also cannot be safely ignored. 
In the following, I proceed through Stobaeus' text and attempt to demonstrate (1) that good sense can be made of it as it stands without emendation; and (2) we need not dismiss its testimony, or posit a confused source for Stobaeus, but can understand Cleanthes' intervention as more akin to a development of the orthodox Stoic account than to a polemical attack on the positions of either Zeno and Chrysippus. This is not to suggest, of course, that all the problems of this text can be solved; however, I do claim that the barbed points of its aporiai can be blunted.

Stobaeus' text is as follows:

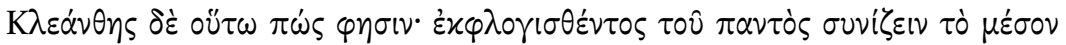

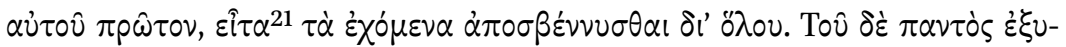

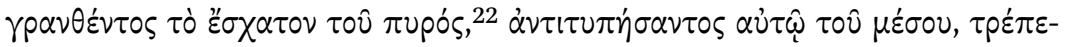

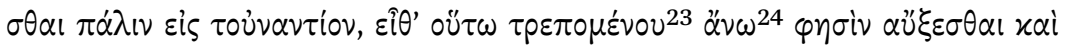

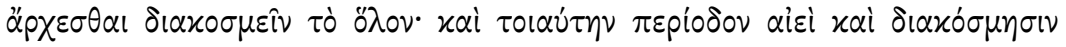

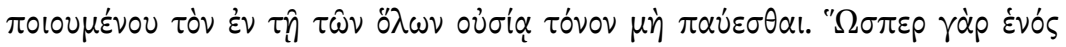

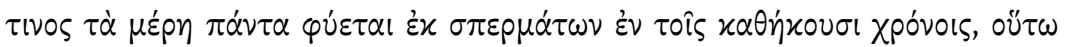

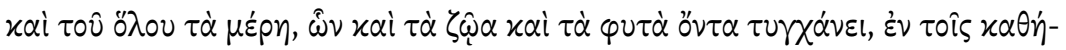

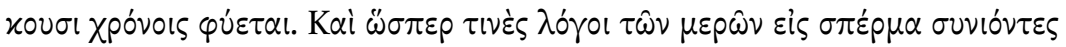

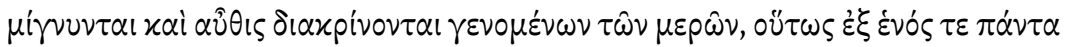

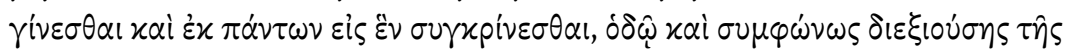
$\pi \varepsilon p เ o ́ \delta \circ .^{25}$

This passage immediately follows Stobaeus' presentation of Zeno's position on the ordering of the cosmos conforming, in the most important details, to the description found in Diogenes. Clearly, we are meant to distinguish Cleanthes' view from Zeno's, but we are given no direct indication how we are to account

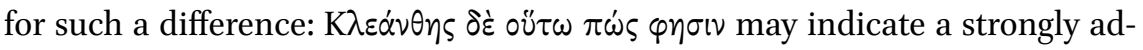
versative, polemic gap between the two, as Salles's reading suggests, or a mere difference in their approaches. Let us see how this might work.

\footnotetext{
21 Von Arnim adds $x \alpha \tau \dot{\alpha}$ here.

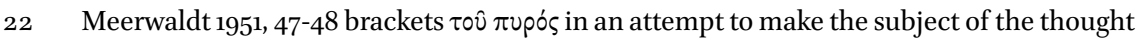

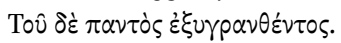

$23 \tau \rho \varepsilon \pi \dot{o} \mu \varepsilon v o v$ is read by Canter. I defend the manuscript reading below.

$24 \dot{\alpha}^{\prime} \nu \omega \theta \varepsilon \nu$ is suggested by von Arnim, on the basis that "ignis in altissima tantum caeli parte relictus nunc ad inferiores regiones paulatim descendens crescit et omnia format atque disponit".

25 Stob. 153.7-22 Wachsmuth. हiৎ cf. Arist. Metaph. 985a24-26.
} 
Our difficulties begin almost immediately. The aorist $\dot{\varepsilon} \varkappa \varphi \lambda \circ \gamma\left(\sigma \theta \varepsilon \dot{\varepsilon} \tau \varsigma^{26}\right.$ suggests the conflagration has already been completed and the whole has become 'flame' $\left(\varphi \lambda \sigma^{\prime} \xi\right) .{ }^{27}$ Yet Cleanthes seems to diverge quickly from this familiar account by suggesting that the cosmogonic process begins at the spatial middle

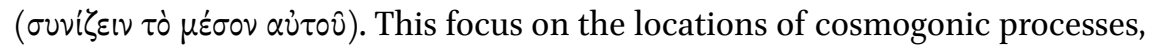
working out from the middle to the spatial extremes of the whole, is unique to Cleanthes on Stobaeus' account, and has led to a great deal of confusion in the

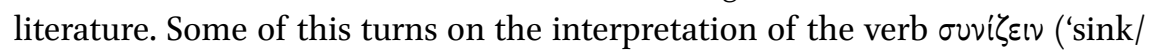
collapse'), which figures heavily in previous accounts. Both Hahm and Salles draw a strong connection between the word and the formation of earth. ${ }^{28}$ Certainly, two extant scholia $(S V F$ 1.104; 2.565) discuss Stoic elemental transformation using the verb to indicate a change into earth. However, it is mis-

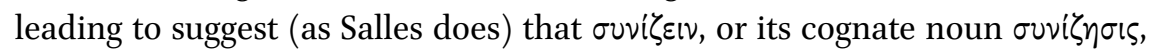
indicates anything exclusively tied to transformation into earth. Philo's discussion of the Stoic cosmogony using this vocabulary makes this clear:

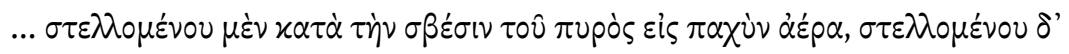

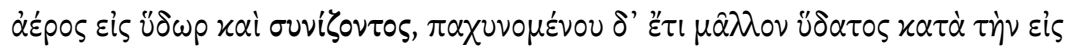

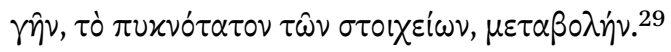

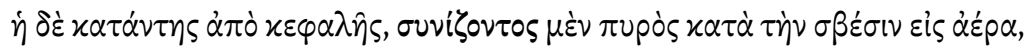

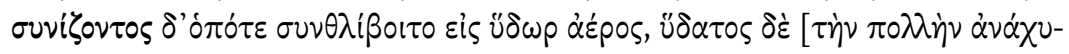

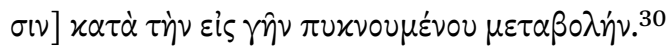

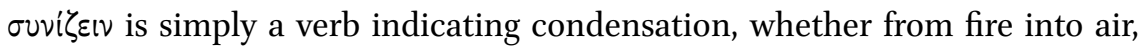
air to water, or water to earth. Although the scholia Salles marshals do use the verb to indicate compression into earth, there is no reason to privilege its use in relation to the densest element or to think that Cleanthes is concerned with the specific formation of earth at the start of world formation. ${ }^{31}$

26 See Cooper 2009, 105 n. 26 for the importance of understanding the sense of the aorist in such a cosmogonical context.

27 See Philo, Aet. Mun. 9o = SVF 1.511 for the distinction between Cleanthes and Chrysippus

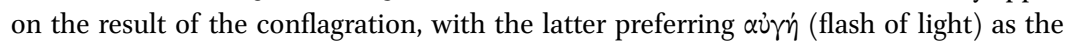
final product from which the cosmogony begins.

28 Hahm 1977, 241; Salles 2015, 23-25.

29 Philo, Aet. Mun. 103.

30 Philo, Aet. Mun. 110-111.

31 Hahm 1977, 244-245 makes something like this point, somewhat undercutting his analysis on 241. See Meerwaldt 1951, 47-48 quoting Philo, 110; however, he is concerned to demonstrate (incorrectly, in my view) that Cleanthes is concerned particularly with the 


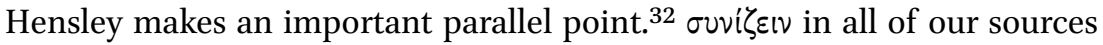
(including the scholia) refers to the process of increasing elemental density. Yet Salles's understanding is significantly different. The verb, on his account, would point not to a transformation of fire into earth (this, of course, would skip the usual preliminary changes through air and water) but to the gradual build-up of earth at the centre of the cosmos as a residue from the conflagration. Such a build-up remains a permanent feature, surviving conflagrations. Yet this seems very distant from the consistent use of ouvígıv elsewhere, and it appears far more likely to indicate a transformation from fire into a denser element.

If this is right, Salles's suggestion that Cleanthes' idea behind the use of ouvi$\zeta \varepsilon \varepsilon v$ is that there is some remnant or 'residue' of earth left behind by the conflagration that ultimately works to extinguish the fire, I think, must be rejected. ${ }^{33}$

What we must minimally take away is that Cleanthes' cosmogony starts with a condensation of flame (which the whole has become) in the middle. Thus we are situated in the context of elemental transformation understood on the Stoic line as the result of processes of condensation and rarefaction. ${ }^{34}$ Such elemental transformation, according to condensation and rarefaction, from fire to earth and back again, is explicitly attributed to Chrysippus, and there is strong reason to believe that Cleanthes maintained a similar position. ${ }^{35}$

From the spatial, location-centric perspective that Cleanthes' seems to adopt, what is important is that our evidence suggests that the whole itself is subject to contraction and expansion. Both Plutarch and Philo note that the rarefaction of the whole into fire means that its boundaries are pushed outwards at the point of total conflagration. ${ }^{36}$ Beginning at the middle, Cleanthes

formation of fire into air here. He is right, however, to avoid any implication of earth formation in this first process.

32 Hensley forthcoming, ${ }^{*} 22-{ }^{*} 25$.

33 An appeal to $S V F 1.495$ does little to help here. In this evidence from Hermias, Cleanthes

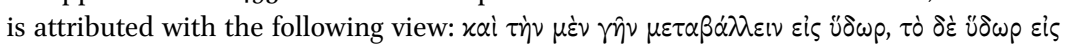

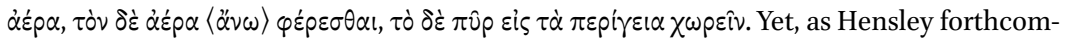
ing, *25 notes in his criticism, this is not clearly referring to the cosmogony. All that is discussed is elemental change, a standard feature of Stoic cosmology. Nor does this text oblige us to understand that fire is a remnant from the conflagration. The first two points here refer to elemental transformation; the second two to the natural movements of air and fire. No logical or chronological priority of the elements need be assumed here.

34 Plu. De comm. not. = Mor. 1077b, Aët. Plac. 2.4.13 = SVF 2.597

35 For Chrysippus, see $S V F 2.413$ in particular. Hermias ( $S V F$ 1.495) attributes the reverse process of transformation (from earth to fire) to Cleanthes, suggesting he had developed an understanding of the process of the elemental transformation.

36 Philo Aet. Mun. 102-3; Plu. De comm. not. = Mor. 1077b. See, too, Cleom. 1.101-103. Of course, the presence of extra-cosmic void in the Stoic system allows for such expansion. 
is suggesting that cosmogony is a process of condensation that works from the inside out, ultimately reducing the size $\tau \dot{o} \pi \hat{\alpha} \nu$ reached in its fiery, rarefied state. It is perfectly compatible that such a process proceeds through the stages described by Diogenes (fire to air to water) prior to elemental formation from water. Fire is condensed through a series of turnings (tropai) into heavier elements.

Thus we need not find any specific place for earth in this first cosmogonic step, despite what its location in the middle might suggest. In any case, all that is required here is that the middle of the whole has condensed. What has it been condensed into? This is left unsaid, but in the next section it becomes clear that Cleanthes holds that it is water-not earth—that has formed at the centre.

The next cosmogonic stage proceeds outwards from the middle. There has been some debate about what is entailed by the process of quenching ( $\dot{\alpha} \pi 0-$ $\sigma \beta \varepsilon \dot{v} v v \sigma \theta \alpha l)$ here. Meerwaldt has emphasised the formation of air from fire, Hahm and Salles have noted that water is the clear result of the process, as

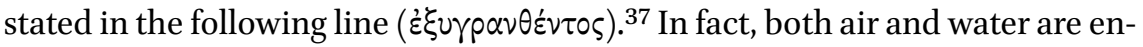
tailed: quenching is the process of transforming fire into water through air. This

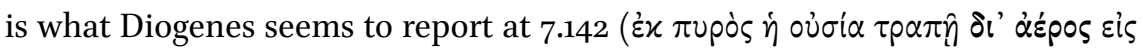

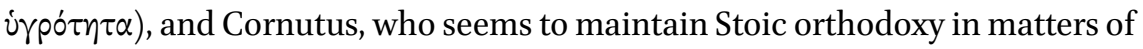
physics, ${ }^{38}$ provides a useful account of the cosmogonic $\sigma \beta \varepsilon \dot{\sigma} \sigma \varsigma$ confirming this understanding of the process:

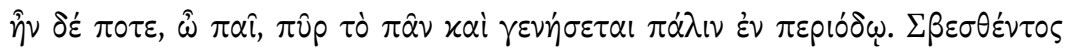

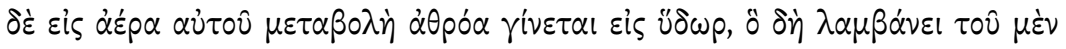
نे

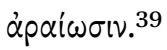

Everything, my child, was once fire, and will be again when the cycle comes round. On being quenched to become air, an overwhelming change occurs to turn it into water, which it controls, compressing part of substance to make it settle, and rarefying part to make it finer.

37 Meerwaldt 1951, 47-48; Hahm 1977, 241; Salles 2015, 25.

38 See Boys-Stones 2018, 29-32.

39 Corn. 28.10-15. Trans. G. Boys-Stones. 
This passage gives us some insight into what the Stoics meant by such cosmogonic quenching. Cornutus confirms the transitional role of air between fire and water, but he also tells us something important about how water comes about. $\alpha \dot{\theta} \rho^{\circ} \alpha$, which Boys-Stones renders as 'overwhelming', is better taken with $\mu \varepsilon \tau \alpha \beta>\lambda \eta$ ' to mean 'change all over at once', as Aristotle twice uses this unusual phrase in his Physics (186a10-16, 253b25). ${ }^{40}$ In the first instance, Aristotle is criticising the Presocratic Melissus for conflating coming-to-be at some time and coming-to-be at some point in space. The thought is that change can occur over its subject all at once. ${ }^{41}$ In the second example, freezing is given as an example of change that is not divisible into spatial parts, even if its subject (e.g. a lake) is so divisible. If this is the sense of $\alpha \theta \rho o ́ \alpha \mu \varepsilon \tau \alpha \beta \circ \lambda \dot{\eta}$ for Cornutus, quenching transforms fire into air and, then, that air is all over simultaneously turned into water.

It is just this point about simultaneity that Cleanthes seems to reject at the scale of the 'whole', although $\delta$ ' ' $\partial 20 u$ seems to suggest that the idea is preserved at a more local level. The part of the 'whole' contiguous to the centre is com-

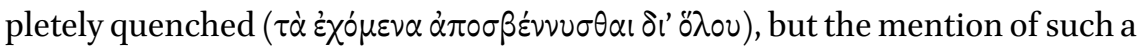
location implies a non-simultaneous process from a macro-perspective, beginning from the centre and moving outwards towards the extremes. ${ }^{42}$

Diogenes' report is ambiguous on this point of simultaneity, and it is tempting to think that the location descriptions that structure Stobaeus' text indicate something of Cleanthes' distinctive contribution to the Stoic theory, where cosmogonic processes are construed as radiating outwards from the originary point at the middle. In any case, such a view is compatible in principle with what we learn from Diogenes, even if Cornutus suggests a competing model emerged diverging from Cleanthes by insisting on simultaneous rather than progressive stages.

What brings about the quenching process? We do not learn the result of the condensation of the middle. It is, of course, possible that it is earth that results and helps to cool the contiguous portion of fire. However, we hear in

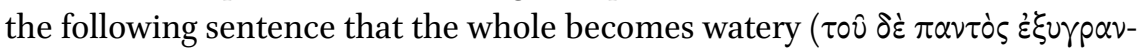

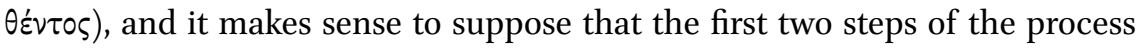
described by Stobaeus correspond to the move from fire, through air, into water in the traditional account. Fire is condensed (through air in a quenching process) into water at the middle; such a process moves outwards until the whole has been transformed into water. So far, what distinguishes Cleanthes'

40 Cf. Plu. Cor. 29.3.2.

41 See Harriman 2018, 89-91 and Bostock 2006, 104-107.

42 Hensley forthcoming, ${ }^{*} 20$ rightly notes this aspect of Cleanthes' cosmogony. 
understanding from the traditional account is not be found in the structure of elemental transformation but in the details of their progressive generation.

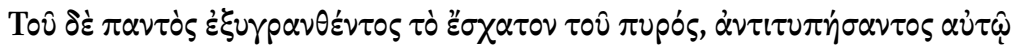

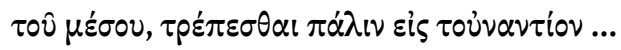

Here we find the participial structure of the first sentence repeated with the aorist indicating that the whole has become a watery mass. Yet we are sur-

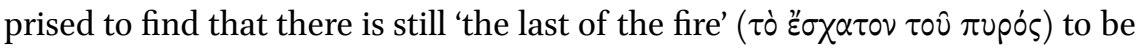
found. How can the 'whole' have become watery and fire still be present? By supposing water, and not earth, to be at the centre, we have addressed a difficulty Salles and others must face, but the presence of fire is still a point of tension. ${ }^{43}$ Meerwaldt solves this worry by bracketing $\tau 0 \hat{~} \pi$ upós, but there are no sound textual reasons for doing so. ${ }^{44}$

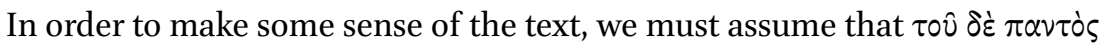

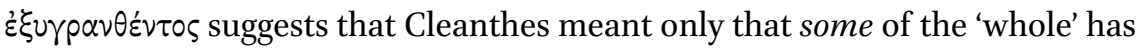
become watery, i.e. the transformation of fire through air into water has occurred. To say that something has become watery, even using the aorist, need not imply that this has occurred to the whole of the subject. The idea, then, is that the 'whole' has reached the stage of water creation and that, once this

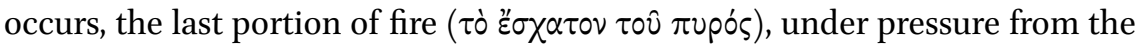

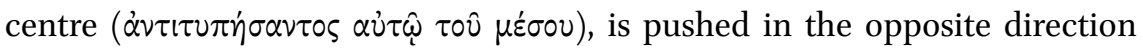

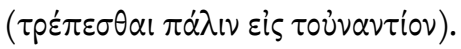

What is meant by the 'last portion of fire'? It perhaps seems clear, as often assumed, that in Stobaeus' tripartite structure this is the peripheral fire left after the centre and its surrounds have been transformed into water and that this remains un-transformed. This is what Hensley seems to have in mind when he suggests that, as the centre increases in density, the peripheral fire maintains its contact with the core using centripetal motion. ${ }^{45}$ Yet an alterna-

43 As Hahm 1977, 243 neatly puts it: “'The all having become wet' [is] a summary more appropriate to a state in which the cosmos is totally water (as in the orthodox cosmogony) than the cosmic state implied by Stobaeus with earth at the center, water in between, and fire surviving at the periphery". He thinks this is evidence that someone has misunderstood Cleanthes' sincere commitment to the orthodox view, which has been misleadingly developed by an intermediary.

44 Meerwaldt 1951, 47.

45 Hensley forthcoming, ${ }^{*} 20-{ }^{*} 21$. 
tive seems possible. The 'last' may simply be the extreme inner edge ${ }^{46}$ of the fire that is pushed outwards as the 'whole' progressively transforms into water, starting from the centre. We are to take the 'turning of the fire in the opposite

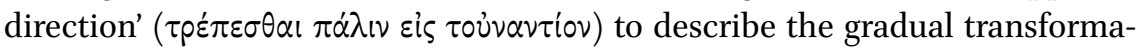
tion of the surrounding fire into water as it is quenched. On this view, the 'last of the fire' is pushed further and further away from the centre as the remaining fire is quenched to form water through air. The 'resistance' ( $\dot{\alpha} \nu \tau i \tau v \pi \eta \dot{\eta} \sigma \alpha \nu$ -

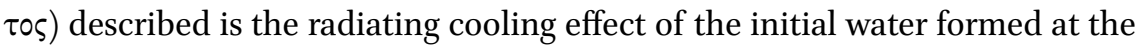
centre. ${ }^{47}$ This suggests that both centripetal and centrifugal motion is relevant. The peripheral fire does maintain contact with the condensing centre centripetally, but the transformation of the fire into water through air is centrifugally pushing the mass of the core outwards. ${ }^{48}$

The virtue of this reading is that we need not account for the sudden movement of the fire, nowhere previously mentioned. Nor do we need to wonder what is meant by 'resistance', if we understand that what is entailed is the process of quenching, radiating outwards from the centre, that Cleanthes has in mind.

What distinguishes this suggestion from the others on offer is that the remaining fire is not simply moved outwards to form the heavens and begin the $\delta\llcorner\alpha x \delta ́ \sigma \eta\rceil \varsigma \zeta$ of the familiar universe. Rather, this fire is eventually transformed into water and it is from this watery state that $\delta 1 \alpha x \delta \sigma \mu \eta \sigma i \varsigma$ can begin, as it does on the other accounts of the Stoic cosmogony. ${ }^{49}$

The basic structure of Diogenes' orthodox account is in place, only the details of the progression of the early stages of the cosmogony have been

46 है $\sigma \alpha \alpha \tau \circ$ is normally taken as 'outermost', but it need not imply anything more than a border or limit, cf. Pl. Phd. 113b; often enough, it simply means 'end' or 'extreme', as in Hdt.

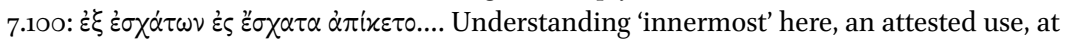
least seems worth consideration, cf. S. Tr. 1053.

47 Of course, the gap between the centre and the periphery is itself narrowed by the progress of the condensation of fire. However, this need not imply that such condensation overtakes it speed moving outwards.

48 Such a reading avoids attributing two opposed motions to fire; one moving from the periphery inwards, and one moving outwards after contact with the middle.

49 See Sen. Nat. 3.13.1-2 for his clear statement of what he takes to be the Stoic position (Dicimus enim ignem esse qui occupet mundum et in se cuncta convertat; hunc evanidum languentemque considere et nihil relinqui aliud in rerum natura igne restincto quam umorem; in hoc futuri mundi spem latere). Incidentally, it is distinctly odd, if Cleanthes did indeed have a strongly unorthodox view on cosmogony, that we have no indication of this outside of what interpreters make of the Stobaeus passage. Seneca, for example, perfectly willing to point to early, intra-school debates (e.g. Ep. 113.23), indicates no such break on the cosmogony in Nat. Hensley forthcoming, ${ }^{*} 23$ also raises this worry. 
developed. We need not, I suggest, accept that any of the fire of the conflagration (i.e. fire that burns fuel) remains. ${ }^{50}$

The above suggestion is novel, but I take it that it gains support from the following, concluding statement which provides the last piece of information on the specifics of Cleanthes' view of the cosmogonic process. We may provisionally translate: 'And then he says that, moving upwards, it grows in size and begins to order the universe'.

What is our subject? This important question has been obscured by a widely accepted correction to the manuscripts that need not be accepted. $\tau \rho \varepsilon \pi \dot{\mu} \mu \varepsilon v o v$ for $\tau \rho \varepsilon \pi \circ \mu \varepsilon$ vंov, proposed by Canter, suggests it is the fire that moves upwards, grows in size, and starts the $\delta i \alpha \delta_{\sigma} \sigma \mu \eta \sigma \iota \zeta$, i.e. the formation of the cosmic - not proto, as we have been discussing — elements from which the familiar world is constructed. The appeal of this is obvious; as discussed above, the importance of the $\pi \hat{v} \rho \tau \varepsilon \kappa v i x^{\prime} v^{51}$ to the Stoic providential creation of the world is clear, and one might be tempted to think that it is this designing fire that Cleanthes equates with the 'last of the fire'. Yet there is no reason to think that Cleanthes veered so sharply from the standard Stoic account (D.L. 7.135-136 above, SVF $2.6 \circ 5,1.98$ ) that the divine fire is contracted and understood as 'sperm' or 'soul' within proto-water as a 'seminal principle' and brings about the world order. Of course, Cleanthes is himself credited with introducing the notion of 'vital heat' to Stoic physics (Cic. N.D. 2.23-5), but this does not imply that such a principle is identical to the fire of the cosmogony. Fire, I take it, is only to be understood as a permanent feature of the universe on the basis that, at the moist start of $\delta \iota \alpha x^{\prime} \sigma \mu \eta \sigma \varsigma$, it exists only in the form of fiery 'sperm' or 'soul', i.e. as the manifestation of the divine active principle. ${ }^{52}$

Preferring the manuscript reading of $\tau \rho \varepsilon \pi \circ \mu \varepsilon$ v $0 v$ provides an alternative to

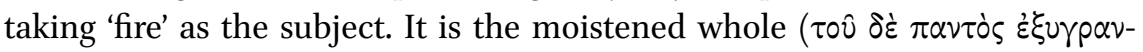

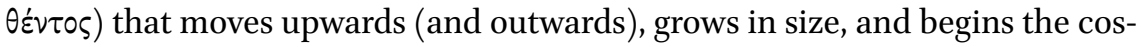

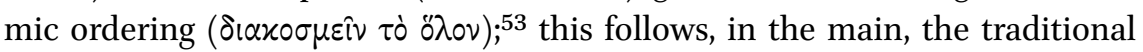

$5^{\circ} \quad$ This is just what is implied by our central pieces of evidence, including $S V F 1.102$ and $S V F$ 2.581, where cosmic fire comes about from the thinning of cosmic air.

$5^{1} \quad$ See $S V F$ 2.1027.

$5^{2}$ See Cooper 2009 particularly 112-113 for the clearest account.

53 Here we can assume that Cleanthes' proto-water contains the 'sperm' or 'soul' of the initial divine fire and, thus, the seminal principle that orders the cosmos. 
view that proto-water is the proximate source of the four cosmic elements, which make up familiar, complex bodies. ${ }^{54}$

However, an immediate worry with such a reconstruction is that Stoic cosmology does not typically assign outwards and upwards motion to the dense element of water. Cleanthes does seem to attribute explicitly the former to

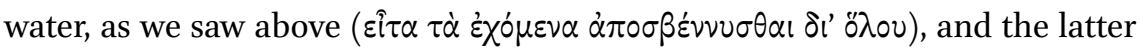

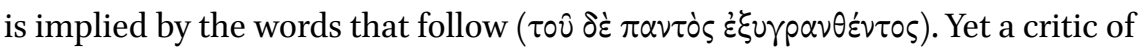
my interpretation of the subject of $\tau$ $\varepsilon \pi \circ \mu \varepsilon$ vo might reasonably note that fire (or air) seems a more likely candidate for the element that moves upwards.

One response to this worry is that, on any account of Cleanthes' cosmogony, some understanding of the radiating motion of water will be required to capture its essentially progressive nature, independently of whether the above reconstruction is accepted. Salles, for example, explains the movement of water

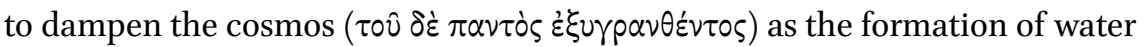
vapour that pervades the whole cosmos. ${ }^{55}$

A second point to note is that we need not assume that what is true of cosmic water is also true of the proto-element. The 'moisture' Diogenes describes in the pre-cosmic stage of cosmogony where Zeus envelops himself for the creation of the cosmic four elements simply need not be understood as having the same properties as the familiar element. Indeed the idea that he remains in this moisture in order to make 'matter serviceable to himself for the next stage of creation' suggests that we strongly distinguish this pre-cosmic 'moisture' from the cosmic element. 'Moisture', it is implied, is not suitable for functioning in the tight causal nexus of the developed Stoic cosmos where distinctive elemental characteristics will be required.

The advantage of this interpretation is that it is fully consistent with our evidence of Cleanthes' adherence to the Stoic view of cosmic $\alpha v \alpha \theta u \mu i \alpha \sigma i \zeta$, whereby the sun is held to be sustained by exhalations from moisture, making the fiery heavenly bodies posterior to the formation of cosmic water. ${ }^{56}$ If the substance of the heavenly bodies pre-exists the formation of water as survivors of the conflagration, there is a prima facie inconsistency in Cleanthes' physics. ${ }^{57}$ However, the larger worry is that cosmic exhalation is used by Cleanthes, and the Stoics more generally, to mirror their theory of the human soul as nourished

54 Here I am following von Arnim ( $S V F$ 1.111, apparatus): "illud praefero (i.e. $\tau \rho \varepsilon \pi \circ \mu \varepsilon ́ v 0 u$ ), quia non ignem conferti, sed aquosam globi partem constat", although I doubt his emendation of the following $\ddot{\alpha} v \omega$ to $\ddot{\alpha} v \omega \theta \varepsilon v$.

55 Salles 2015, 25 .

$5^{6} \quad$ This view is widespread in Stoicism (see $S V F$ 1.121, 2.652, 2.65o) and explicitly attributed to Cleanthes ( $S V F$ 1.501).

Salles 2015, 30 recognises this but does not address the worry here. 
by moisture. ${ }^{58}$ The appeal to a microcosm/macrocosm model is of particular importance for Cleanthes, who appeared to rely on such cosmic models. ${ }^{59}$ It is also significant that he is said to have discounted human nature from the standard Stoic telos of living according to nature; this further centralizes the importance of these physical models and of the value of microcosm/macrocosm analogies outside of 'mere' physics. ${ }^{60}$ If this is right, an inconsistency in Cleanthes' view of the makeup of the heavenly bodies threatens the foundations of both his account of the physical word and the normative, ethical claims that turn on his natural philosophy.

Indeed such a worry puts into perspective the importance of the text we have been considering. It is not simply the details of Cleanthes' view on cosmogony that are at stake but our understanding of how those details relate to the Stoic exploration of what it means to live in accordance with nature. Fortunately, we need not freight Cleanthes with the conflicted view that cosmic fire is a remnant of the conflagration that instigates the process of $\delta$ เ $x^{\circ} \sigma \mu \eta \sigma i \varsigma$.

The above interpretation finds far less novelty in Cleanthes' account of the conflagration than some have maintained. However, I also reject the claim that our passage from Stobaeus simply misconstrues what is, in fact, Cleanthes' basic commitment to what I have called the traditional, or orthodox, view found in Diogenes and supported by Plutarch and Philo. The broad framework of that account is indeed to be found in our passage; however, this does not imply that there is no evidence of development or elaboration. In fact, the emphasis on the beginning stages of cosmogony as location-specific processes does seem to be Cleanthes' distinctive contribution to the theory; the transformations of the proto-elements are presented as radiating outwards from their originary location at the middle.

However, it is important to note that the development I have ascribed to Cleanthes is not inconsistent with what Diogenes suggests was the standard view. The basic schema of proto-elemental transformation from fire through

\footnotetext{
$5^{8}$ See, for example, Arius Didymus on Cleanthes' explication of Zeno using Heraclitus at $S V F$ 1.141, containing Heraclitus B12. For a helpful account, and a list of relevant passages, see Mansfeld 2015, 70-75.

59 For discussion of $\alpha \nu \alpha \theta \nu \mu i \alpha \sigma \iota s$ and microcosm/macrocosm, see Tieleman 1996, 90-96. For Cleanthes' use of such a model in the crucial area of his theory of vital heat, see Cic. N.D. 2.40-41, and possibly 42-43 (on which, see Hahm 1977, 269-272). 
air into water is maintained. I suggest too that both Zeno and Cleanthes take the fire of the conflagration to be extinguished and cosmic fire to result from the rarefaction of cosmic air. This is what our evidence from Stobaeus and Diogenes suggests.

What makes this significant is that it helps to frame our understanding of how natural philosophy was developed in the early Stoa. While it is relatively easy to find discussions of polemical, intra-school debate between Cleanthes and Chrysippus, determining how Cleanthes and the other early Stoics develop Zeno's physics is less obvious. ${ }^{61}$ However, it does seem plain that Zeno left quite a bit of room for development here for his successors and wrote relatively little on natural philosophy. ${ }^{62}$ Judging by our lists of book titles, Cleanthes and his pupil, Sphaerus, produced significantly more work on physics, and the for-

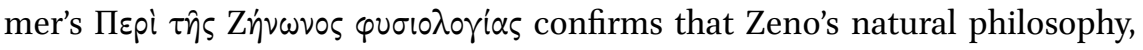
however fully worked out it was, was defended and developed by his immediate followers. ${ }^{63}$

The theory of the conflagration is a special case in this regard. ${ }^{64}$ Very little of Zeno's physical works survive in verbatim form with the notable exception of his argument for the total conflagration, preserved by the Neoplatonist Alexander Lycopolis. ${ }^{65}$ What does this suggest? At the very least it implies two constraints for his successors: (1) the articulation of this area of cosmology in the early Stoa was not as fully in need of elaboration as others, and (2) respecting Zeno's authority was a relevant concern here perhaps more than elsewhere. Later developments of areas Zeno specifically worked out were typically, and formally, cast as interpretations of what the founder really intended rather than as new philosophical directions. ${ }^{66}$

This puts Cleanthes' contribution to the Stoic theories of conflagration and cosmogony in context. Zeno, according to the passage from Alexander

61 Most famously on the kataleptic impression (S.E. M. 7.227-241), but also on the unity of the virtues (Plu. De St. rep. 1034c-e), and on the definition of 'walking' (Sen. Ep. 113.23), which turns on the understanding of the role of pneuma.

62 On Zeno's contribution to Stoic physics, see especially Algra 2003. Zeno certainly wrote

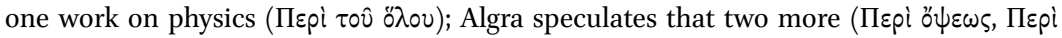
$\sigma \eta \mu \varepsilon i(\omega v)$ may also be belong to this domain. That Zeno left a great deal of room for the development of the system of Stoic philosophy (particularly in its physics) is widely agreed on. For his influential formulation of this idea, see Sedley 1989, 98-99. See Long 2018 for a recent development of this thesis.

63 For Cleanthes' defence and development of Zeno, see Ar.Did. fr. $39=S V F$ 1.519. For the book titles of Cleanthes and Sphaerus, see D.L. 7.174-175 and 7.178.

64 See Algra 2003, 31 n. 45.

$65 \quad 19.2-4=$ LS 46 I. For discussion of this passage (NB: not in SVF), see Mansfeld 1979, 147-155.

66 See Sedley 2003, 15-17 for this point and several examples. 
Lycopolis, insisted on three points: (1) the cosmos is combustible; (2) the conflagration will completely consume everything; and (3) the fire of the conflagration will consume its fuel and be extinguished. ${ }^{67}$ Readers of our Stobaeus passage have thought Cleanthes to be in direct opposition to the last two of these claims, i.e. that he maintained either that something survives the conflagration or the fire of conflagration is never fully extinguished, or both. As I have suggested, neither can safely be attributed to Cleanthes, but we are none the worse for finding him to be a careful developer of the core Stoic doctrine of $\dot{\varepsilon} x \pi \dot{v} \omega \omega \sigma \iota s$, rather than a polemical renegade challenging one of the areas of natural philosophy that Zeno does seem to have articulated in some detail.

\section{Bibliography}

LS = Long and Sedley 1987.

Algra, K. (2003). Zeno of Citium and Stoic Cosmology. Some Notes and Two Case Studies. Elenchos 24, pp. 9-32.

von Arnim, H. (1921). Kleanthes. RE 11, pp. 563-564.

Bostock, D. (2006). On the Eleatics in Physics I. In: D. Bostock, ed., Space, Time, Matter, and Form, Oxford, pp. 103-115.

Boys-Stones, G.R. (2018). L. Annaeus Cornutus. Greek Theology, Fragments, and Testimonia. Atlanta, GA.

Canter, W. (1575). Ioannis Stobaei Eclogarum libri duo; quorum prior physicas, posterior ethicas complectitur; nunc primum Graece editi. Antwerp.

Colson, F.H. (1941). Philo, Vol. 9. Cambridge, MA.

Cooper, J.M. (2009). Chrysippus on Physical Elements. In: R. Salles, ed., God and Cosmos in Stoicism, Oxford, pp. 93-117.

Dorandi, T. (2013). Diogenes Laertius, Lives of Eminent Philosophers. Cambridge.

Gourinat, J.-P. (2009). The Stoics on Matter and Prime Matter. In: R. Salles, ed., God and Cosmos in Stoicism, Oxford, pp. 46-70.

Hahm, D.E. (1977). The Origins of Stoic Cosmology. Ohio.

Harriman, B. (2018). Melissus and Eleatic Monism. Cambridge.

Hensley, I. (forthcoming). The Physics of Stoic Cosmogony. Apeiron. Published online ahead of publication https://doi.org/10.1515/apeiron-2018-oo97.

Long, A.A., and Sedley, D.N. (1987). The Hellenistic Philosophers. (2 vols). Cambridge.

Long, A.A. (2018). In and Out of the Stoa. Diogenes Laertius on Zeno. In: J. Warren, Bryan, J. and R. Wardy, eds., Authors and Authorities in Ancient Philosophy, Cambridge, pp. 242-262.

$67 \quad$ Salles 2015, 28-29 neatly summarises Zeno's argument. 
Mansfeld, J. (1979). Providence and the Destruction of the Universe in Early Stoic Thought. With Some Remarks on the 'Mysteries of Philosophy'. In: M.J. Vermaseren, ed., Studies in Hellenistic Religions, Leiden, pp. 129-188.

Mansfeld, J. (2015). Heraclitus on Soul and Super-Soul with an Afterthought on the Afterlife. Rhizomata 3, pp. 62-93.

Meerwaldt, J.D. (1951) Cleanthea. Mnemosyne 4/4, pp. 40-69.

Pearson, A.C. (1891). The Fragments of Zeno and Cleanthes. London.

Salles R. (2009). Chrysippus on Conflagration and the Indestructibility of the Cosmos. In: R. Salles, God and Cosmos in Stoicism, Oxford, pp. 118-134.

Salles, R. (2015). Two Early Stoic Theories of Cosmogony. In: A. Marmodoro and B.D. Prince, eds., Causation and Creation in Late Antiquity, Cambridge, pp. 11-30.

Sedley, D. (1989). Philosophical Allegiance in the Greco-Roman World. In: M. Griffin and J. Barnes, eds., Philosophia Togata, Cambridge, pp. 97-119.

Sedley, D. (2003). The School, From Zeno to Arius Didymus. In: B. Inwood, ed., The Cambridge Companion to the Stoics, Cambridge, pp. 7-32.

Tieleman, T. (1996). Galen and Chrysippus on the Soul. Leiden. 